\title{
ОСОБЕННОСТИ ТЕХНОЛОГИЙ РЕАЛИЗАЦИИ ДИАЛОГА-ПЕРЕЖИВАНИЯ В ПРАКТИКЕ ОБРАЗОВАТЕЛЬНОГО ПРОЦЕССА
}

\author{
Ирина А. Рудакова ${ }^{1 *}$, Татьяна В. Мирошниченко ${ }^{2}$
}

${ }^{1}$ Кубанский государственный университет, г. Краснодар,

Российская Федерачия

${ }^{2}$ Южно-Российский государственный политехнический университет (НПИ) имени М. И. Платова, г. Новочеркасск, Российская Федерация *E-mail: irina_rudak@mail.ru

Разработка технологий реализации диалога-переживания в практике образовательного прочесса осуществлена на основании: 1) выяснения роли смысловых переживаний, участвующих в прочессах накопления смыслов, их сравнения и порождения новых смыслов, обусловленных прежде всего потребностями обучающихся в понимании других людей и себя; персонализачии и персонификации, личностных способов их реализации - в образах, смысловых конструктах и диспозициях, а также в направленности; 2) уточнения роли эмоционально-эмпатийных, образных и рефлексивных переживаний, обеспечивающих смысловое согласование смысловых позиций участников диалога при формировании совместного отношения к учебной деятельности; их координации при формировании межличностных отношений в момент «входа» в учебную деятельность, а также трансформации смысловых структур в межгрупповом взаимодействии при выполнении совместно-творческой деятельности через феномены «отраженной субъектности» - образ Другого, образ значимого Другого, персонифичированный образ значимого Другого.

В соответствии с особенностями функционирования эмоциональноэмпатийных, образных и рефлексивных переживаний обучающихся выделены и описаны обобщенные технологии, сгруппированные в три блока, характеризующие направления психологчческой, психолого-педагогической и педагогической поддержки обучающихся в учебном прочессе. В каждом блоке представлены по три направления технологий более частного порядка. Среди них: снижение негативных переживаний, восстановление «недостающих» переживаний, формирование позитивных переживаний (психологический блок технологий); персонифицированное обучение, технологии командообразования, рефлексивные технологии (психолого-педагогический блок); технологии, направленные на решение вопросов контакности, сотворчества, 
сотрудничества в совместно-творческой деятельности (педагогический блок).

Разработанные технологии реализации диалога-переживания в практике образовательного прочесса, во-первых, позволят «развернуть» обучающегося в сторону Другого, а во-вторых, обеспечат педагогу «мягкое» управление в учебном прочессе.

Ключевые слова: уровни, компоненты диалога-переживания, смысловые переживания, эмоционально-эмпатийные переживания, образные переживания, рефрлексивные переживания, отраженная субъектность, обобщенные технологии, частные технологии.

Для цитирования: Рудакова И. А., Мирошниченко Т. В. Особенности технологий реализации диалога-переживания в практике образовательного процесса // Российский психологический журнал. - 2017. - Т. 14. - № 1. - С. 124-134.

Материалы статьи получены 19.11.2016

UDC 37.026 .9

doi: $10.21702 /$ rpj.2017.1.8

\title{
FEATURES OF THE DIALOGUE-EXPERIENCE TECHNIQUES IN THE EDUCATIONAL PROCESS
}

\author{
Irina A. Rudakova ${ }^{* *}$, Tat'yana V. Miroshnichenko ${ }^{2}$ \\ ${ }^{1}$ Kuban State University, Krasnodar, Russian Federation \\ 2 Platov South-Russian State Polytechnic University (NPI), Novocherkassk, \\ Russian Federation \\ *Correspondence author. E-mail: irina_rudak@mail.ru
}

Elaborating the dialogue-experience techniques in the educational process relied on the following: (a) revealing the role of sense experiences in sense accumulation processes, as well as their comparison and generating new senses, conditioned by learners' need for understanding themselves and other people; (b) studying personalization and personification, personal ways of their implementation (in images, sense constructs and dispositions, as well as in orientation); (c) clarifying the role of emotional and empathic, figurative, and reflective experiences which provide sense harmonization of dialogue participants' sense stands when forming the joint relation to educational activities; (d) studying the role of the coordination of these experiences in forming interpersonal relationships in educational activities, as well as the transformation of sense structures in inter-group interaction when performing 
co-creative activities through the phenomena of "reflected subjectivity" (the image of Another, the image of significant Another, and the personified image of significant Another).

In accordance with the features of learners' emotional and empathic, figurative, and reflective experiences, the analysis highlighted and described the generalized techniques. These techniques fell into three blocks determining the direction of psychological, psycho-pedagogical, and pedagogical support of learners in the educational process. Each block included the following three groups of more particular techniques: (a) lowering negative experiences, restoring "missing" experiences, and forming positive experiences (the psychological block of techniques); (b) personified education, techniques of team building, and reflective techniques (the psychopedagogical block of techniques); techniques for solving the issues of sociability, co-creation, and cooperation in co-creative activities (the pedagogical block of techniques).

The developed dialogue-experience techniques can "turn" the learner to Another and enable the teacher to manage the educational process in a "soft" manner.

Keywords: levels, dialogue-experience components, sense experiences, emotional and empathic experiences, figurative experiences, reflective experiences, reflected subjectivity, generalized techniques, particular techniques.

For citation: Rudakova I. A., Miroshnichenko T. V. Features of the dialogueexperience techniques in the educational process. Rossiiskii psikhologicheskii zhurnal - Russian Psychological Journal, 2017, V. 14, no. 1, pp. 124-134 (in Russian).

Original manuscript received 19.11.2016

\section{Введение}

Актуальность темы исследования обусловлена, во-первых, общей проблематикой исследования смысловых коммуникаций, рассматриваемых как направленная трансляция смыслов в образовательном процессе. В психолого-педагогических исследованиях подчеркивается, что современные старшеклассники испытывают затруднения в общении с одноклассниками, учителями, родителями, испытывают состояние психологического дискомфорта при осознании своей сущности, смысловой перспективы своего образования и личностного самоопределения. В исследованиях О. Е. Байтингер, Д. Н. Демидова, Л. А. Регуш и др. обосновывается, что проблемы, связанные со значимым Другим, переживаются респондентами подросткового и раннего юношеского возрастов как наиболее личностно значимые.

Во-вторых, актуальность разрабатываемой темы исследования обусловлена спецификой диалога в смысловой интерпретации. В психолого-педагогических 
разработках достаточно подробно описан феномен диалога с разных теоретико-методологических подходов; выделены его типы в контексте активности личности: экзистенциальный диалог, интенциональный (Е. П. Александров, М. В. Воронцова, Т. А. Дубровская, Н. Е. Зыбина и др.), эмпатийный (О. В. Бочкарёва, С. В. Бочкарёва, Н. А. Коваль и др.), рефлексивный (Г. И. Давыдова, А. В. Измагурова, В. Л. Росохин), смысловой диалог (Н. Ю. Гусевская, Е. В. Зеленов, М. А. Лукьяненко, Л. П. Самойлов и др.).

Что касается диалога-переживания, то имеется небольшое число исследований, в которых диалог-переживание выделяется среди других типов высоким уровнем смысловой насыщенности (И. В. Абакумова, И. А. Рудакова, В. В. Суфиянов) $[1,17,22]$, предложена его обобщенная психологическая модель (И. В. Абакумова, И. Н. Нестеренко) [1, 10]. В психологических исследованиях Д. А. Леонтьева подчеркнута деятельность переживания как внутренней работы сознания по критической перестройке смысловых структур при соприкосновении с иным смыслом [9]. Эта новая смыслостроительная функция переживания в диалоге наиболее рельефно проявляется в ситуациях «личностных вкладов».

Однако вопрос о том, какими технологиями реализуется диалог-переживание в учебном процессе, недостаточно решен в педагогической науке.

Цель исследования состоит в раскрытии особенностей технологий реализации диалога-переживания в учебном процессе. Объект исследования - учебный процесс высокой смысловой насыщенности. Предмет исследования - особенности технологий реализации диалога-переживания в практике образовательного процесса. Задачи исследования: выделить и кратко описать уровни и компоненты структурно-функциональной модели диалога-переживания; кратко охарактеризовать переживания, которые участвуют в диалоге-переживании; систематизировать технологии, направленные на реализацию диалога-переживания в практике образовательного процесса.

\section{Основная часть}

Диалог-переживание относится к особому типу диалогов смысловой трансляции в учебном процессе [1, 19]. Его особенность состоит в том, что переживание осуществляет смысловое согласование позиций участников диалогового взаимодействия, их смысловую координацию и трансформацию на всех этапах учебной деятельности и уровнях общения $[9,21]$.

В диалоге смысловые переживания участвуют в накоплении смыслов (смысловой индукции), их сравнении (смысловой идентификации), а также трансформации (полагания смысла) [7, 9]. Эти процессы определяют в диалоге-переживании наличие трех структурных уровней: предсмыслового, смыслового и метасмыслового. На каждом из них обучающийся использует 
личностные способы реализации потребности в социальном восприятии других людей, потребности быть личностью и быть самим собой [4]. На предсмысловом уровне - это образы как предвестники смыслов. На смысловом уровне - смысловые конструкты и диспозиции. На метасмысловом уровне - направленность.

На каждом из уровней функционирования диалога-переживания особую роль выполняет Другой [17]. На предсмысловом уровне в процессе смысловой индукции при формировании совместного отношения к учебной деятельности присутствует Другой, точнее, его образ, что позволило выделить компонент «присутствие» [3]. На смысловом уровне в процессе смысловой идентификации при формировании межличностных отношений возникает образ значимого Другого, что позволило выделить компонент «сопричастность» [14]. На метасмысловом уровне в процессе полагания смыслов в межгрупповом взаимодействии участвует персонифицированный образ значимого Другого, что позволило выделить компонент «включенность» [7].

В компонентном составе модели диалога-переживания раскрывается специфика «личностных вкладов». В компоненте «присутствие» через образ Другого как своеобразного ресурса осознается значимость «личностных вкладов» каждого участника диалога друг для друга [2]. В компоненте «сопричастность» через образ значимого Другого как своеобразного идентификатора осознается «личностный вклад» Другого «для меня». В компоненте «включенность» через персонифицированный образ значимого Другого как своеобразного трансцендентора осознается значимость «меня для Других».

В смысловом согласовании, координации и трансформации смысловых позиций участников диалога-переживания активно участвуют специфические эмоционально-эмпатийные, образные и рефлексивные переживания.

На предсмысловом уровне эмоционально-эмпатийные переживания представлены неосознаваемыми, актуальными переживаниями. Образные переживания (образы-архетипы) отражают момент формирования образа Другого. Рефлексивные переживания связаны с прошлым опытом обучающегося.

На смысловом уровне эмоционально-эмпатийные переживания, в основном, принимают характер оценки - позитивности и негативности. Образные переживания (образы-представления) участвуют в формировании образа значимого Другого. Рефлексивные переживания отражают текущее, актуальное состояние личности обучающихся.

На метасмысловом уровне эмоционально-эмпатийные переживания раскрываются экзистенциальными переживаниями. Образные переживания (образы творческого воображения) обеспечивают «построение» персонифицированного образа значимого Другого. Рефлексивные переживания выходят на уровень метарефлексии. 
Особенности трех типов переживаний обусловливают выбор трех групп технологий реализации диалога-переживания в практике образовательного процесса: технологий, основанных на эмоционально-эмпатийных переживаниях (первая группа); технологий, сориентированных на образные переживания (вторая группа); технологий, раскрывающих особенности функционирования в диалоге-переживании рефлексивных переживаний (третья группа).

В психологических исследованиях можно отметить использование первой группы технологий [20]: направленные на снижение негативных переживаний (психотерапевтический подход Ф. Е. Василюка) [5]; восстановление недостающих (неиспытанных) переживаний (диалогово-центрированный подход Н. А. Погодина) [13]; формирование позитивных переживаний (психодинамический подход Д. А. Леонтьева) [9]. Эта группа технологий включена в «Психологический блок».

В рамках психолого-педагогических разработок к технологиям на образной основе можно отнести: персонифицированное обучение с идеей отраженной субъектности (латеральные, дивергентные, конвергентные технологии) [13]; методы командообразования с идеей принятия Другого (тимбилдинг, тимдесинг, ретиминг и тимфорсинг) [15]; рефлексивные технологии с идеей персонификации образа значимого Другого [10, 23]. Эта группа технологий образует «Психолого-педагогический блок».

В педагогических исследованиях можно отметить многочисленную группу технологий, ориентированных, в основном, на конкретные компоненты диалога-переживания, где проявляются все типы переживаний.

Первую группу составляют: технологии построения процесса обучения на эмоционально-образной основе (Н. Г. Осадченко) [11]; технологии возбуждения эмоций (остранение, изменение логической или временной последовательности и др.); технологии эффективного (эмпатического, рефлексивного) слушания (М. В. Талалаева и др.), отражающие содержание компонента «присутствие» и отвечающие на вопрос, как обеспечить открытость диалогу.

В состав второй группы входят: смыслопорождающие технологии (Н. Н. Лубянова, Е. В. Шоган и др.) [18]; технологии создания ситуаций ценностно-смыслового выбора (Н. Н. Мироненкова); технологии предметно-смыслового диалога (Н. И. Сулейманова) [16], отражающие содержание компонента «сопричастность» и отвечающие на вопрос создания условий для смыслового выбора в принятии/непринятии Другого.

Третью группу образуют: технологии включенности в совместную деятельность (Б. В. Куприянов, В. В. Островская) [12]; смыслопоисковые технологии с акцентом на эмоциональные переживания (Е. В. Зеленов) [8]; техники создания перспективных линий (А. В. Гребенкин) [6], отражающие содержание 
компонента «включенность» и отвечающие на вопрос построения смысловой перспективы в персонифицированном образе значимого Другого. Эти группы технологий образуют «Педагогический блок».

В зависимости от типов переживаний выделенные три группы технологий могут быть названы обобщенными, раскрывающимися технологиями частного порядка, что подводит к выводу о широком спектре оказания психологической, психолого-педагогической и педагогической помощи обучающемуся в учебном процессе.

\section{Выводы}

Особенности реализации диалога-переживания в практике образовательного процесса обусловлены:

1) во-первых, пониманием диалога-переживания как особого типа диалога смысловой трансляции в учебном процессе, направленного на трансформацию смысловых позиций его участников посредством смысловых переживаний;

2) во-вторых, типами эмоционально-эмпатийных, образных, рефлексивных переживаний, специфика которых наиболее рельефно проявляется в ситуациях «личностных вкладов»;

3) в-третьих, функционированием обобщенных групп технологий, раскрывающихся, в свою очередь, технологиями частного порядка и определяющих направления психологической, психолого-педагогической и педагогической поддержки обучающихся.

\section{Литература}

1. Абакумова И. В., Ермаков П. Н., Рудакова И. А. Смыслоцентризм в педагогике: новое понимание дидактических методов. - Ростов н/Д: Изд-во Рост. ун-та, 2006. - 256 с.

2. Асмолов А. Г. Психология личности: культурно-историческое понимание развития человека. - М.: Смысл, 2007. - 528 с.

3. Барсукова С. А. Присутствие как психологический феномен, проявляющийся в отношениях «человек-мир» // Актуальные проблемы психологии личности: сб. ст. по матер. II междунар. науч.-практ. конф. - Новосибирск: Изд-во СибАК, 2010. - № 2. - Часть І. - С. 32-35.

4. Бочкарёва С. В. Специфика и возможности эмпатического познания: автореф. дисс. ... канд. философ. наук. - Курган, 2011. - 24 с.

5. Василюк Ф. Е. Понимающая психотерапия как психотехническая система: автореф. дисс. ... д. психол. наук. - М., 2007. - 48 с.

6. Гребенкин A. Психологические аспекты актерского мастерства // URL: http://theater111.ru/science18.php 
7. Ермишкина Е.Н. Педагогическое взаимодействие как совместно-распределенная деятельность // Новое слово в науке и практике: гипотезы и апробация результатов исследований: сборник материалов XII Международной научно-практической конференции / Под общ. ред. С. С. Чернова. - Новосибирск: Изд-во ЦРНС, 2014. - С. 65-69.

8. Зеленов Е. В. Педагогические условия становления ценностно-смысловых ориентаций старшеклассников в процессе художественно-эстетической деятельности: автореф. дисс. ... канд. пед. наук. - М., 2012. - 24 с.

9. Леонтьев Д. А. Психология смысла: природа, строение и динамика смысловой реальности. 2-е, испр. издание. - М.: Смысл, 2003. - 487 с.

10. Нестеренко И. Е. Психолого-дидактические особенности формирования смысловых установок старшеклассников в учебном процессе: автореф. дисс. ... канд. психол. наук. - Ростов н/Д, 2009. - 23 с.

11. Осадченко Н. Г., Фоменко В. Т. Модель построения процесса обучения на образно-эмоциональной основе: монография. - Ростов н/Д: Изд-во РО ИПК и ПРО, 2010. - 150 с.

12. Островская В. В. Экзистенциальный диалог как метод изучения авторского сознания в современной прозе на уроке литературы в старших классах // Журнал научных публикаций аспирантов и докторантов. 2008. - № 12. - С. 38-42.

13. Погодин И. А. Теория и методология психотерапии, фокусированной на переживании: диалогово-феноменологический подход // Консультативная психология и психотерапия. - 2014. - № 3 (82). - С. 93-104.

14. Погорелов А. Г. Психологические характеристики личности на уровне сопричастности к деятельности // Известия Южного федерального университета. Технические науки. - 1998. - № 1 (7). - С. 48-54.

15. Ситников В. Л. Педагогика общей заботы - источник современной психологии командообразования // Российский гуманитарный журнал. - 2014. - Т. 3. - № 2. - С. 86-97.

16. Сулейманова Н. И. Формирование ценностно-смысловой сферы у младших школьников средствами предметно-смыслового диалога в совместно-разделенной деятельности // Известия Самарского научного центра Российской академии наук. - 2010. - Т. 12. - № 5-1. С. 156-162.

17. Суфиянов В. В. Диалог как педагогическая технология в смыслообразующем учебном контексте: автореф. дисс. ... канд. пед. наук. Ростов н/Д, 2007. - 24 с.

18. Шоган Е. В. Экзистенциальные диалоги как фактор ценностно-смыслового развития личности старшеклассника в образовательном пространстве школы: автореф. дисс. ... канд. пед. наук. - Ростов н/Д, 2006. - 26 с. 
19. Best B., Blake A., Varney J. Making Meaning: Learning through LogoVisual Thinking. - Cambridge: Chris Kington Publ., 2005.

20. Dervin B. Sense-Making's Journey from Metatheory to Methodology to Methods: An Example Using Information Seeking and Use as Research Focus // Sense-Making Methodology Reader. - Cresskill, NJ: Hampton Press, 2003. - pp. 141-146.

21. Hermans H. J. M. The dialogical self: toward a theory of personal and cultural positioning // Culture \& Psychology. - 2001. - V. 7 (3). - pp. 243-281.

22. Klein G., Moon B., Hoffman R. Making Sense of Sensemaking 2: A Macrocognitive Model // Intelligent Systems (IEEE). - V. 21. - no. 5. - pp. 88-92.

23. Kolko J. Sensemaking and Framing: A Theoretical Reflection on Perspective in Design Synthesis // Proceedings of the 2010 DRS Montreal Conference. Montréeal: Design Research Society, 2010.

\section{References}

1. Abakumova I. V., Ermakov P. N., Rudakova I. A. Smyslotsentrizm v pedagogike: novoe ponimanie didakticheskikh metodov [Sense-centrism in pedagogy: A new understanding of didactic methods]. Rostov-on-Don, Rostov State University Publ., 2006. 256 p.

2. Asmolov A. G. Psikhologiya lichnosti: kul'turno-istoricheskoe ponimanie razvitiya cheloveka [Personality psychology: A cultural-historical understanding of human development]. Moscow, Smysl Publ., 2007. 528 p.

3. Barsukova S. A. Prisutstvie kak psikhologicheskii fenomen, proyavlyayushchiisya v otnosheniyakh «chelovek-mir» [Presence as a psychological phenomenon manifesting itself in "the man - the world" relations]. Aktual'nye problemy psikhologii lichnosti: sb. st. po mater. II mezhdunar. nauch.-prakt. konf. [Proc. the Second International Theoretical and Practical Conference "Actual problems of personality psychology"]. Novosibirsk, SibAK Publ., 2010, no. 2, Part I, pp. 32-35.

4. Bochkareva S. V. Spetsifika i vozmozhnosti empaticheskogo poznaniya [The specificity and potential of empathic cognition]. Diss. Cand. Sci. (Philos.). Kurgan, 2011.

5. Vasilyuk F. E. Ponimayushchaya psikhoterapiya kak psikhotekhnicheskaya sistema [Understanding psychotherapy as a psychotechnical system]. Diss. Dr. Sci. (Psych.). Moscow, 2007.

6. Grebenkin A. Psychological aspects of acting. [Online]. Available at: http:// theater111.ru/science18.php

7. Ermishkina E. N. Pedagogicheskoe vzaimodeistvie kak sovmestno-raspredelennaya deyatel'nost'[Pedagogical interaction as a joint distributed activity]. Novoe slovo v nauke i praktike: gipotezy i aprobatsiya rezul'tatov issledovanii: 
sbornik materialov XII Mezhdunarodnoi nauchno-prakticheskoi konferentsii [Proc. the XII International Theoretical and Practical Conference "Innovations in science and practice: hypotheses and testing results research"]. Novosibirsk, TsRNS Publ., 2014, pp. 65-69.

8. Zelenov E. V. Pedagogicheskie usloviya stanovleniya tsennostno-smyslovykh orientatsii starsheklassnikov $v$ protsesse khudozhestvenno-esteticheskoi deyatel'nosti [Pedagogical conditions for sense-value orientations of senior pupils in artistic and aesthetic activity]. Diss. Cand. Sci. (Pedag.). Moscow, 2012.

9. Leont'ev D. A. Psikhologiya smysla: priroda, stroenie i dinamika smyslovoi real'nosti [The psychology of sense: nature, structure, and dynamics of sense reality]. Moscow, Smysl Publ., 2003. 487 p.

10. Nesterenko I. E. Psikhologo-didakticheskie osobennosti formirovaniya smyslovykh ustanovok starsheklassnikov v uchebnom protsesse [Psycho-didactic features of forming senior pupils' sense attitudes in the learning process]. Diss. Cand. Sci. (Psych.). Rostov-on-Don, 2009.

11. Osadchenko N. G., Fomenko V. T. Model' postroeniya protsessa obucheniya na obrazno-emotsional'noi osnove [The model of the learning process on the imaginative and emotional basis]. Rostov-on-Don, RO IPK \& PRO Publ., 2010. $150 \mathrm{p}$.

12. Ostrovskaya V. V. Existential dialogue as a method of studying of an author's consciousness in modern prose at literature lessons in high school. Zhurnal nauchnykh publikatsii aspirantov i doktorantov - Journal of Scientific Publications of Post-Graduate Students and Doctoral Candidates, 2008, no. 12, pp. 38-42 (in Russian).

13. Pogodin I. A. Theory and methodology of experience-focused psychotherapy: a dialogue and phenomenological approach. Konsul'tativnaya psikhologiya i psikhoterapiya - Counseling Psychology and Psychotherapy, 2014, no. 3 (82), pp. 93-104 (in Russian).

14. Pogorelov A. G. Psychological features of personality at the level of involvement in activity. Izvestiya Yuzhnogo federal'nogo universiteta. Tekhnicheskie nauki - Proceedings of Southern Federal University. Engineering science, 1998, no. 1 (7), pp. 48-54 (in Russian).

15. Sitnikov V. L. The pedagogy of a common concern as a source of the modern psychology of team building. Rossiiskii gumanitarnyi zhurnal - Liberal Arts in Russia, 2014, V. 3, no. 2, pp. 86-97 (in Russian).

16. Suleimanova N. I. Forming junior schoolchildren's sense-value sphere by means of the subject-sense dialogue in joint distributed activity. Izvestiya Samarskogo nauchnogo tsentra Rossiiskoi akademii nauk - Proceedings of the Samara Scientific Center of the Russian Academy of Sciences, 2010, V. 12, no. 5-1, pp. 156-162 (in Russian). 
17. Sufiyanov V. V. Dialog kak pedagogicheskaya tekhnologiya v smysloobrazuyushchem uchebnom kontekste [Dialogue as a pedagogical technique in the sense-creating educational context]. Diss. Cand. Sci. (Pedag.). Rostovon-Don, 2007.

18. Shogan E. V. Ekzistentsial'nye dialogi kak faktor tsennostno-smyslovogo razvitiya lichnosti starsheklassnika vobrazovatel'nom prostranstve shkoly [Existential dialogues as a factor of a senior pupils'sense-value development in the educational space of school]. Diss. Cand. Sci. (Pedag.). Rostov-on-Don, 2006.

19. Best B., Blake A., Varney J. Making Meaning: Learning through LogoVisual Thinking. Cambridge, Chris Kington Publ., 2005.

20. Dervin B. Sense-Making's Journey from Metatheory to Methodology to Methods: An Example Using Information Seeking and Use as Research Focus. In: Sense-Making Methodology Reader. Cresskill, NJ, Hampton Press, 2003, pp. 141-146.

21. Hermans H. J. M. The dialogical self: toward a theory of personal and cultural positioning. Culture \& Psychology, 2001, V. 7 (3), pp. 243-281.

22. Klein G., Moon B., Hoffman R. Making Sense of Sensemaking 2: A Macrocognitive Model. Intelligent Systems (IEEE), V. 21, no. 5, pp. 88-92.

23. Kolko J. Sensemaking and Framing: A Theoretical Reflection on Perspective in Design Synthesis. In: Proceedings of the 2010 DRS Montreal Conference. Montréeal, Design Research Society, 2010. 